Kong Mun Lo, See Mun Lee and Edward R.T. Tiekink*

\title{
Crystal structure of $\mathbf{N}$-methyl- $\mathbf{N}$-phenyl (methylsulfanyl)carbothioamide, $\mathrm{C}_{9} \mathrm{H}_{11} \mathrm{NS}_{2}$
}

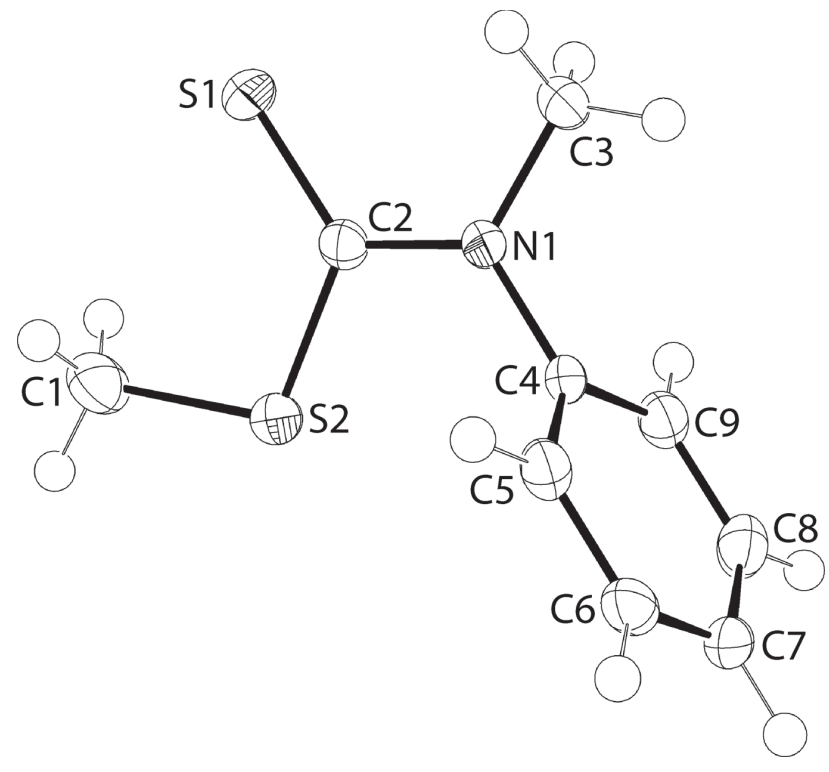

https://doi.org/10.1515/ncrs-2019-0511

Received July 18, 2019; accepted August 25, 2019; available

online September 12, 2019

\section{Abstract \\ $\mathrm{C}_{9} \mathrm{H}_{11} \mathrm{NS}_{2}$, monoclinic, $P 2_{1} / n \quad$ (no. 14), $\quad a=5.6183$ (1) $\AA$, $b=18.2426(3) \AA, \quad \quad c=9.5185(2) \AA, \quad \beta=96.835(2)^{\circ}$, $V=968.64(3) \AA^{3}, Z=4, R_{\mathrm{gt}}(F)=0.0303, w R_{\text {ref }}\left(F^{2}\right)=0.0826$, $T=100(2) \mathrm{K}$.}

\section{CCDC no.: 1948963}

The molecular structure is shown in the figure. Table 1 contains crystallographic data and Table 2 contains the list of the atoms including atomic coordinates and displacement parameters.

\footnotetext{
*Corresponding author: Edward R.T. Tiekink, Research Centre for Crystalline Materials, School of Science and Technology, Sunway University, 47500 Bandar Sunway, Selangor Darul Ehsan, Malaysia, e-mail: edwardt@sunway.edu.my. https://orcid.org/0000-00031401-1520

Kong Mun Lo and See Mun Lee: Research Centre for Crystalline Materials, School of Science and Technology, Sunway University, 47500 Bandar Sunway, Selangor Darul Ehsan, Malaysia
}

Table 1: Data collection and handling.

\begin{tabular}{|c|c|}
\hline Crystal: & Colourless prism \\
\hline Size: & $0.17 \times 0.09 \times 0.04 \mathrm{~mm}$ \\
\hline Wavelength: & Cu $K \alpha$ radiation $(1.54184 \AA$ ) \\
\hline$\mu:$ & $4.51 \mathrm{~mm}^{-1}$ \\
\hline Diffractometer, scan mode: & XtaLAB Synergy, $\omega$ \\
\hline$\theta_{\max }$, completeness: & $67.1^{\circ},>99 \%$ \\
\hline$N(h k l)_{\text {measured }}, N(h k l)_{\text {unique }}, R_{\text {int }}:$ & $11698,1735,0.050$ \\
\hline Criterion for $I_{\mathrm{obs}}, N\left(h k l_{\mathrm{gt}}:\right.$ & $I_{\text {obs }}>2 \sigma\left(I_{\text {obs }}\right), 1558$ \\
\hline$N(\text { param })_{\text {refined }}:$ & 111 \\
\hline Programs: & $\begin{array}{l}\text { CrysAlis }{ }^{P R O}[1] \text {, SHELX }[2,3] \text {, } \\
\text { WinGX/ORTEP [4] }\end{array}$ \\
\hline
\end{tabular}

Table 2: Fractional atomic coordinates and isotropic or equivalent isotropic displacement parameters $\left(\AA^{2}\right)$.

\begin{tabular}{lrrrr}
\hline Atom & $\boldsymbol{x}$ & $\boldsymbol{y}$ & $\boldsymbol{z}$ & $\boldsymbol{U}_{\text {iso }}{ }^{*} \boldsymbol{U}_{\text {eq }}$ \\
\hline S1 & $0.52898(8)$ & $0.54031(2)$ & $0.22540(5)$ & $0.02023(15)$ \\
S2 & $0.31034(8)$ & $0.65491(2)$ & $0.39930(5)$ & $0.01934(15)$ \\
N1 & $0.6011(3)$ & $0.68373(8)$ & $0.21179(16)$ & $0.0153(3)$ \\
C1 & $0.1812(4)$ & $0.57046(11)$ & $0.4487(2)$ & $0.0257(4)$ \\
H1A & 0.083225 & 0.549454 & 0.366476 & $0.039^{*}$ \\
H1B & 0.080440 & 0.579626 & 0.524144 & $0.039^{*}$ \\
H1C & 0.309249 & 0.536056 & 0.482660 & $0.039^{*}$ \\
C2 & $0.4920(3)$ & $0.62716(10)$ & $0.26972(18)$ & $0.0145(4)$ \\
C3 & $0.7748(3)$ & $0.66948(10)$ & $0.11115(19)$ & $0.0181(4)$ \\
H3A & 0.917919 & 0.646158 & 0.160744 & $0.027^{*}$ \\
H3B & 0.819704 & 0.715878 & 0.069587 & $0.027^{*}$ \\
H3C & 0.702498 & 0.636909 & 0.036002 & $0.027^{*}$ \\
C4 & $0.5614(3)$ & $0.75900(9)$ & $0.24878(18)$ & $0.0146(4)$ \\
C5 & $0.3513(3)$ & $0.79439(10)$ & $0.19358(19)$ & $0.0176(4)$ \\
H5 & 0.233802 & 0.769028 & 0.131899 & $0.021^{*}$ \\
C6 & $0.3147(3)$ & $0.86695(10)$ & $0.22923(19)$ & $0.0190(4)$ \\
H6 & 0.170928 & 0.891202 & 0.192572 & $0.023^{*}$ \\
C7 & $0.4874(3)$ & $0.90418(10)$ & $0.31828(19)$ & $0.0186(4)$ \\
H7 & 0.461426 & 0.953743 & 0.343003 & $0.022^{*}$ \\
C8 & $0.6988(3)$ & $0.86889(11)$ & $0.37137(19)$ & $0.0206(4)$ \\
H8 & 0.817922 & 0.894582 & 0.431345 & $0.025^{*}$ \\
C9 & $0.7357(3)$ & $0.79614(10)$ & $0.33673(19)$ & $0.0180(4)$ \\
H9 & 0.879708 & 0.771934 & 0.373098 & $0.022^{*}$ \\
\hline & & & &
\end{tabular}

\section{Source of material}

All chemicals and solvents were used as purchased without purification. The melting point was determined using a Meltemp II digital melting point apparatus and was uncorrected. The solid-state IR spectrum was obtained on a Bruker Vertex 
70v FTIR Spectrometer from 4000 to $400 \mathrm{~cm}^{-1}$. The ${ }^{1} \mathrm{H}$ and ${ }^{13} \mathrm{C}\left\{{ }^{1} \mathrm{H}\right\}$ NMR spectra were recorded at room temperature in DMSO- $\mathrm{d}_{6}$ solution on a Bruker Ascend $400 \mathrm{MHz}$ NMR spectrometer with chemical shifts relative to tetramethylsilane.

The dithiocarbamate ligand was prepared in situ (acetone) from the reaction of $\mathrm{CS}_{2}$ (Merck, $0.25 \mathrm{mmol}$ ) with $\mathrm{N}$-methylaniline (Merck, $0.25 \mathrm{mmol}$ ) and $\mathrm{NaOH}(0.02 \mathrm{~mL}$; $50 \% \mathrm{w} / \mathrm{v}) ; \mathrm{CS}_{2}$ was added dropwise into the acetone solution $(15 \mathrm{ml})$. The resulting mixture solution was kept at $273 \mathrm{~K}$ for $1 \mathrm{~h}$. Next, dimethyltin dichloride (Merck, $0.25 \mathrm{mmol}, 0.055 \mathrm{~g}$ ) in acetone $(10 \mathrm{ml})$ was added into the solution and the resulting mixture was stirred for $2.5 \mathrm{~h}$. The filtrate was evaporated until a white precipitate was obtained. The precipitate was washed with $n$-hexane and recrystallized from a methanol-acetone solution. The title ester was a side-product obtained from the slow evaporation of the solvent. Yield: 0.005 g (10.2\%). M.pt: 481-483 K. IR $\left(\mathrm{cm}^{-1}\right) 1490(\mathrm{~m}) \mathrm{v}(\mathrm{C}-\mathrm{N})$, $1112(s) v(C-S), 1082(s) v(C-S) .{ }^{1}$ H NMR (DMSO-d 6 , p.p.m.): $\delta$ 2.85 (s, 3H, $\left.\mathrm{SCH}_{3}\right), 3.50$ (s, 3H, $\left.\mathrm{NCH}_{3}\right), 6.91-7.30(\mathrm{~m}, 5 \mathrm{H}, \mathrm{Ph}-\mathrm{H})$. ${ }^{13} \mathbf{C}\left\{{ }^{1} \mathbf{H}\right\}$ NMR (DMSO-d 6 , p.p.m.): $\delta 23.5\left(\mathrm{SCH}_{3}\right), 43.1\left(\mathrm{NCH}_{3}\right)$, 121.1, 124.5, 129.1, 138.9 (Ph-C), $197.8\left(\mathrm{CS}_{2}\right)$.

\section{Experimental details}

The C-bound $\mathrm{H}$ atoms were geometrically placed $(\mathrm{C}-$ $\mathrm{H}=0.95-0.98 \AA$ ) and refined as riding with $U_{\text {iso }}(\mathrm{H})=$ $1.2-1.5 U_{\text {eq }}(\mathrm{C})$.

\section{Comment}

Dithiocarbamate ligands $\left({ }^{-} \mathbf{S}_{\mathbf{2}} \mathbf{C N R R}^{\prime}\right)$ are very well known as important ligands for metals/main group elements/lanthanides owing to their strong chelating ability. Recent interest in our laboratories has focused upon the structural chemistry of the homoleptic zinc-triad dithiocarbamates [5] along with their adducts with bipyridyl-type ligands [6]. It is salient to note that even with such a substantial body of structural data [5], in recent years two unprecedented structural motifs for cadmium dithiocarbamates have been discovered $[7,8]$, underscoring the value of systematic and thorough structural studies. An allied focus is upon the evaluation of the potential activity and biological modes of action of metal compounds of this important class of ligands [9], such as anti-cancer activity of bismuth(III) [10, 11] and zinc(II) [12] species, and anti-bacterial activity of gold(I) derivatives $[13,14]$. In this context, it is noteworthy that all-organic, dithiocarbamate esters, $\boldsymbol{R}^{\prime \prime} \mathbf{S}_{\mathbf{2}} \mathbf{C N R} \mathbf{R}^{\prime}$, also attract on-going interest in the context of developing pharmaceuticals $[15,16]$. In view of the above, herein, the crystal and molecular structures of a simple example of a dithiocarbamate ester, namely, $\operatorname{MeSC}(=\mathrm{S}) \mathrm{N}(\mathrm{Me}) \mathrm{Ph}$, are described, which was obtained as a side-product while developing some organotin chemistry (see Source of material).
The title molecule is shown in the figure $(70 \%$ displacement ellipsoids). The central $\mathrm{CNS}_{2}$ residue is strictly planar (r.m.s. deviation $=0.0034 \AA$ ) with the appended C1 [0.096(3) $\AA$ ] and C4 [0.043(3) $\AA$ ] atoms lying to one side of the plane, and the $\mathrm{C} 3[0.1145(0.0027) \AA]$ atom to the other side. The formal C2=S1 double bond of 1.6590(18) Å is significantly shorter that either of the C2-S2 [1.7662(17) $\AA$ ] and C1-S1 [1.789(2) $\AA$ ] bonds. The C2-N1 bond length is 1.351(2) $\AA$, and is considerably shorter than either of the C3-N1 [1.470(2) $\AA$ ] and C4-N1 [1.442(2) $\AA]$ bond lengths. These observations suggest some delocalization of $\pi$-electron density over the central $\mathrm{CNS}_{2}$ chromophore. Nevertheless, the bond angles subtended at the $\mathrm{C} 2$ atom, with those involving the $\mathrm{S} 1$ atom being systematically wider by approximately $10^{\circ}\left[\mathrm{S} 1-\mathrm{C} 2-\mathrm{S} 2=123.47(11)^{\circ}\right.$ and $\left.\mathrm{S} 1-\mathrm{C} 2-\mathrm{N} 1=123.32(13)^{\circ}\right]$ than the third angle [S2-C2$\mathrm{N} 1=113.21(13)^{\circ}$ ], suggest appreciable double-bond character in the $\mathrm{C} 2=\mathrm{S} 1$ bond. The phenyl ring is inclined with respect to the central plane, with the dihedral angle of $77.74(4)^{\circ}$ indicative of an almost orthogonal relationship. This occurs to minimize steric repulsion between the terminal N1-bound residues.

The most prominent supramolecular contact in the molecular packing is a nitrogen-bound-methyl-C$\mathrm{H} \cdot \mathrm{S}$ (ester) interaction $\left[\mathrm{C} 3-\mathrm{H} 3 \mathrm{~b} \cdots \mathrm{S} 2^{\mathrm{i}}\right.$ : $\mathrm{C} 3-\mathrm{H} 3 \mathrm{~b} \cdot \mathrm{S} 2^{\mathrm{i}}=$ $2.86 \AA, \mathrm{C} 3 \cdots \mathrm{S} 2^{\mathrm{i}}=3.8033(19) \AA$ with angle at $\mathrm{H} 3 \mathrm{~b}=162^{\circ}$ for symmetry operation (i) $1 / 2+x, 3 / 2-y,-1 / 2+z$ ]. These interactions lead to a zigzag supramolecular chain along the $c$-axis, being propagated by glide symmetry. The only other contacts of note are sulfur-bound-methyl-C $-\mathrm{H} \cdots \pi$ (phenyl) $\left[\mathrm{C} 1-\mathrm{H} 1 \mathrm{~b} \cdots \operatorname{Cg}(\mathrm{C} 4-\mathrm{C} 9)^{\mathrm{ii}}:=\mathrm{H} 1 \mathrm{~b} \cdots \operatorname{Cg}(\mathrm{C} 4-\mathrm{C} 9)^{\mathrm{ii}}=3.00 \AA\right.$, $\mathrm{C} 1 \cdots \mathrm{Cg}(\mathrm{C} 4-\mathrm{C} 9)^{\mathrm{ii}}=3.841(2) \AA$ with angle at $\mathrm{H} 1 \mathrm{~b}=145^{\circ}$ for (ii) $-1 / 2+x, 3 / 2-y, 1 / 2+z]$. These serve to connect the aforementioned chains into a supramolecular layer in the $a c$-plane. Layers stack along the $b$-axis without directional interactions between them.

To analyse the molecular packing in more detail, Crystal Explorer 17 [17] was utilized, following established procedures [18], to calculate the Hirshfeld surfaces along with the overall and decomposed two-dimensional fingerprint plots in order to ascertain the dominant contacts in the packing. There are three predominant surface contacts, amounting to $99.5 \%$ of the entire surface, i.e. $\mathrm{H} \cdots \mathrm{H}[53.7 \%], \mathrm{S} \cdots \mathrm{H} / \mathrm{H} \cdots \mathrm{S}[27.4 \%]$ and $\mathrm{C} \cdot \mathrm{H} / \mathrm{H} \cdots \mathrm{C}[18.4 \%]$.

The crystal structure of a closely related compound, i.e. $\operatorname{MeSC}(=\mathrm{S}) \mathrm{NMe}_{2}$, is available [19] but, only as a communication to the Cambridge Structural Database. The key geo-

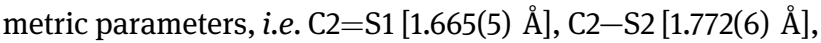
C1-S1 [1.789(7) $\AA]$ and C2-N1 [1.335(6) Å] bear a close similarity to those for the title compound. In terms of molecular packing, no directional interactions are apparent [20]. Accordingly, an analysis of the Hirshfeld surface indicates 
a greater dominance of $\mathrm{H} \cdots \mathrm{H}$ [59.0\%] contacts and significant surface contacts of the type $\mathrm{S} \cdots \mathrm{H} / \mathrm{H} \cdots \mathrm{S}$ [32.1\%], both enhanced compared with the title structure, at the expense of C...H/H .. C [5.9\%] contacts. Other contacts are evident, e.g. $\mathrm{S} \cdot \mathrm{N} / \mathrm{N} \cdots \mathrm{S}[1.3 \%]$ but, at separations greater than the sum of the van der Waals radii.

Acknowledgements: Sunway University Sdn Bhd is thanked for financial support of this work through Grant No. STRRCTR-RCCM-001-2019.

\section{References}

1. Rigaku Oxford Diffraction: CrysAlis ${ }^{P R O}$. Rigaku Corporation, Oxford, UK (2018).

2. Sheldrick, G. M.: A short history of SHELX. Acta Crystallogr. A64 (2008) 112-122.

3. Sheldrick, G. M.: Crystal structure refinement with SHELXL. Acta Crystallogr. C71 (2015) 3-8.

4. Farrugia, L. J.: WinGX and ORTEP for Windows: an update. J. Appl. Crystallogr. 45 (2012) 849-854.

5. Tiekink, E. R. T.: Exploring the topological landscape exhibited by binary zinc-triad 1,1-dithiolates. Crystals 8 (2018) 292.

6. Tiekink, E. R. T.: Perplexing coordination behaviour of potentially bridging bipyridyl-type ligands in the coordination chemistry of zinc and cadmium 1,1-dithiolate compounds. Crystals 8 (2018) 18.

7. Tan, Y. S.; Halim, S. N. A.; Tiekink, E. R. T.: Exploring the crystallization landscape of cadmium bis $(\mathrm{N}$-hydroxyethyl, $\mathrm{N}$-isopropyl-dithiocarbamate), $\mathrm{Cd}\left[\mathrm{S}_{2} \mathrm{CN}(\mathrm{iPr}) \mathrm{CH}_{2} \mathrm{CH}_{2} \mathrm{OH}\right]_{2}$. Z. Kristallogr. - Cryst. Mater. 231 (2016) 113-126.

8. Ahmad, J.; How, F. N.-F.; Halim, S. N. A.; Jotani, M. M.; Lee, S. M.; Tiekink, E. R. T.: A new structural motif for cadmium dithiocarbamates: crystal structures and Hirshfeld surface analyses of homoleptic zinc and cadmium morpholine dithiocarbamates. Z. Kristallogr. - Cryst. Mater. 234 (2019) 341-349.

9. Hogarth, G.: Metal-dithiocarbamate complexes: chemistry and biological activity. Mini Rev. Med. Chem. 12 (2012) 1202-1215.

10. Li, H.; Lai, C. S.; Wu, J.; Ho, P. C.; de Vos, D.; Tiekink, E. R. T.: Cytotoxicity, Qualitative Structure-Activity Relationship (QSAR), and anti-tumor activity of bismuth dithiocarbamate complexes. J. Inorg. Biochem. 101 (2007) 809-816.

11. Ishak, D. H. A.; Ooi, K. K.; Ang, K. P.; Akim, A. M.; Cheah, Y. K.; Nordin, N.; Halim, S. N. B. A.; Seng, H.-L.; Tiekink, E. R. T.: A bismuth diethyldithiocarbamate compound promotes apoptosis in HepG2 carcinoma, cell cycle arrest and inhibits cell invasion through modulation of the NF- $\mathrm{KB}$ activation pathway. J. Inorg. Biochem. 130 (2014) 38-51.

12. Tan, Y. S.; Ooi, K. K.; Ang, K. P.; Akim, A. M.; Cheah, Y.-K.; Halim, S. N. A.; Seng, H.-L.; Tiekink, E. R. T.: Molecular mechanisms of apoptosis and cell selectivity of zinc dithiocarbamates functionalized with hydroxyethyl substituents. J. Inorg. Biochem. 150 (2015) 48-62.

13. Chen, B.-J.; Jamaludin, N. S.; Khoo, C.-H.; See, T.-H.; Sim, J.-H.; Cheah, Y.-K.; Halim, S. N. A.; Seng, H.-L.; Tiekink, E. R. T.: In vitro antibacterial and time kill evaluation of mononuclear phosphanegold(I) dithiocarbamates. J. Inorg. Biochem. 163 (2016) 68-80.

14. Tan, Y. J.; Tan, Y. S.; Yeo, C. I.; Chew, J.; Tiekink, E. R. T.: In vitro anti-bacterial and time kill evaluation of binuclear tricyclohexylphosphanesilver(I) dithiocarbamates, $\left\{\mathrm{Cy}_{3} \mathrm{PAg}\left(\mathrm{S}_{2} \mathrm{CNRR}^{\prime}\right)\right\}_{2}$. J. Inorg. Biochem. 192 (2019) 107-118.

15. Liu, B.; Yuan, X.; Xu, B.; Zhang, H.; Li, R.; Wang, X.; Ge, Z.: Synthesis of novel 7-azaindole derivatives containing pyridin3-ylmethyl dithiocarbamate moiety as potent PKM2 activators and PKM2 nucleus. translocation inhibitors. Eur. J. Med. Chem. 170 (2019) 1-15.

16. Su, Y.; Li, R.; Ning, X.; Lin, Z.; Zhao, X.; Zhou, J.; Liu, J.; Jin, Y.; Yin, Y.: Discovery of 2,4-diarylaminopyrimidine derivatives bearing dithiocarbamate moiety as novel FAK inhibitors with antitumor and anti-angiogenesis activities. Eur. J. Med. Chem. 177 (2019) 32-46.

17. Turner, M. J.; McKinnon, J. J.; Wolff, S. K.; Grimwood, D. J.; Spackman, P. R.; Jayatilaka, D.; Spackman, M. A.: Crystal Explorer v17. The University of Western Australia, Australia (2017).

18. Tan, S. L.; Jotani, M. M.; Tiekink, E. R. T.: Utilizing Hirshfeld surface calculations, non-covalent interaction $(\mathrm{NCl})$ plots and the calculation of interaction energies in the analysis of molecular packing. Acta Crystallogr. E75 (2019) 308-318.

19. Koley, S.; Singh, M. S.: Private communication to the Cambridge Structural Database. Refode: PAMPAX (2016).

20. Spek, A. L.: Structure validation in chemical crystallography. Acta Crystallogr. D65 (2009) 148-155. 